\title{
SUBTASK 4.1 - CONVERSION OF LIGNOCELLULOSIC MATERIAL TO CHEMICALS AND FUELS
}

Final Report

(For the period April 1, 2000 - June 30, 2001)

Prepared for:

AAD Document Control

U.S. Department of Energy

National Energy Technology Laboratory

PO Box 10940, MS 921-143

Pittsburgh, PA 15236-0940

Cooperative Agreement No. DE-FC26-98FT40320

Performance Monitor: Richard B. Read

Prepared by:

Edwin S. Olson

Energy \& Environmental Research Center University of North Dakota

Box 9018

Grand Forks, ND 58202-9018 


\section{DOE DISCLAIMER}

This report was prepared as an account of work sponsored by an agency of the United States Government. Neither the United States Government, nor any agency thereof, nor any of their employees makes any warranty, express or implied, or assumes any legal liability or responsibility for the accuracy, completeness, or usefulness of any information, apparatus, product, or process disclosed or represents that its use would not infringe privately owned rights. Reference herein to any specific commercial product, process, or service by trade name, trademark, manufacturer, or otherwise does not necessarily constitute or imply its endorsement, recommendation, or favoring by the United States Government or any agency thereof. The views and opinions of authors expressed herein do not necessarily state or reflect those of the United States Government or any agency thereof.

This report is available to the public from the National Technical Information Service, U.S. Department of Commerce, 5285 Port Royal Road, Springfield, VA 22161; phone orders accepted at (703) 487-4650.

\section{ACKNOWLEDGMENT}

This report was prepared with the support of the U.S. Department of Energy (DOE) National Energy Technology Laboratory Cooperative Agreement No. DE-FC26-98FT40320. However, any opinions, findings, conclusions, or recommendations expressed herein are those of the authors(s) and do not necessarily reflect the views of DOE.

\section{EERC DISCLAIMER}

LEGAL NOTICE This research report was prepared by the Energy \& Environmental Research Center (EERC), an agency of the University of North Dakota, as an account of work sponsored by DOE. Because of the research nature of the work performed, neither the EERC nor any of its employees makes any warranty, express or implied, or assumes any legal liability or responsibility for the accuracy, completeness, or usefulness of any information, apparatus, product, or process disclosed, or represents that its use would not infringe privately owned rights. Reference herein to any specific commercial product, process, or service by trade name, trademark, manufacturer, or otherwise does not necessarily constitute or imply its endorsement or recommendation by the EERC. 


\section{TABLE OF CONTENTS}

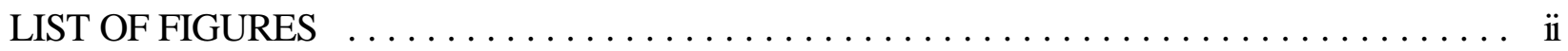

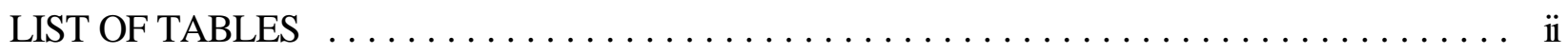

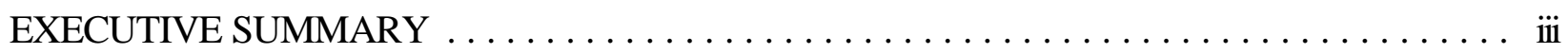

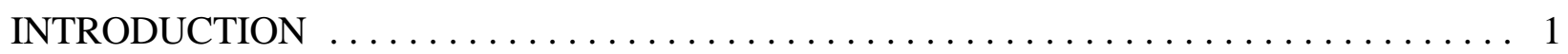

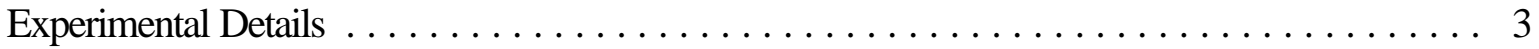

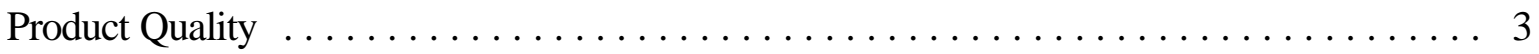

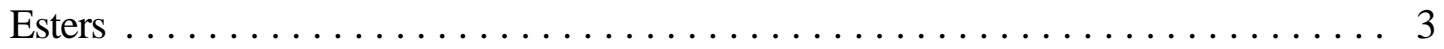

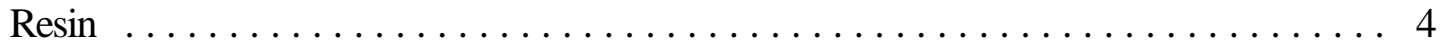

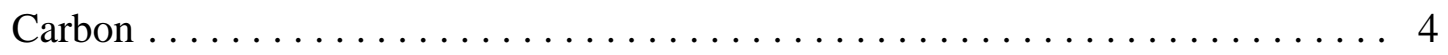

Advantages of the Cellulose Degradation in Ethanol ....................... 4

Particleboard Waste Process Design ............................. 4

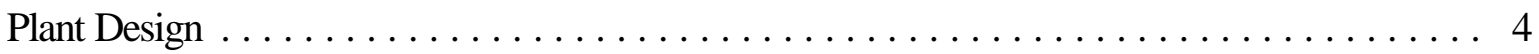

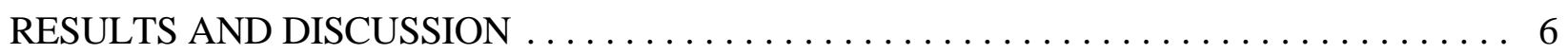

Conversions of Alkyl Levulinates . . . . . . . . . . . . . . . . . . . . . . . 6

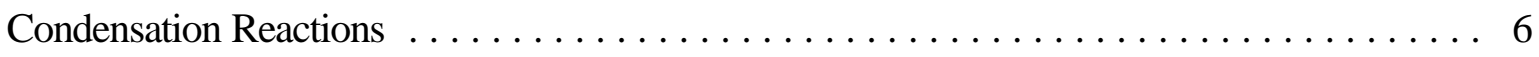

Resin Intermediates . . . . . . . . . . . . . . . . . . . . . 7

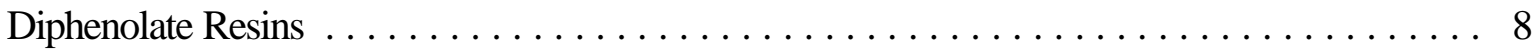

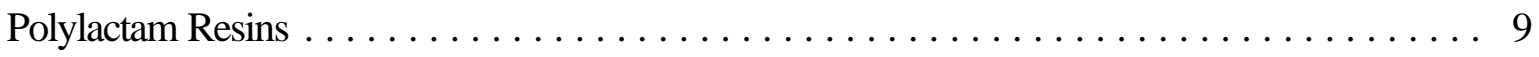

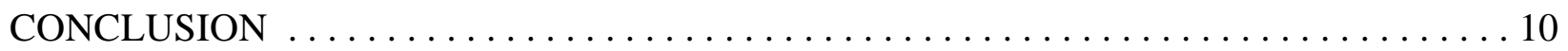

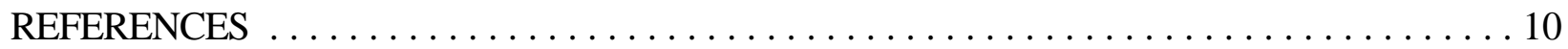




\section{LIST OF FIGURES}

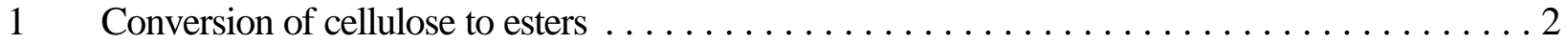

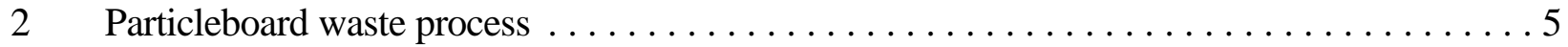

3 Formation of aldehyde condensation product $\ldots \ldots \ldots \ldots \ldots \ldots \ldots \ldots \ldots \ldots$

4 Formation and reactions of diphenolate ester $\ldots \ldots \ldots \ldots \ldots \ldots \ldots \ldots \ldots \ldots$

\section{LIST OF TABLES}

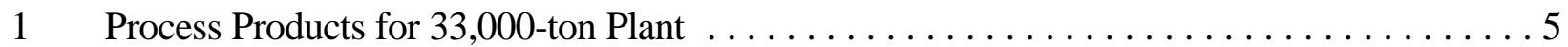




\section{SUBTASK 4.1 - CONVERSION OF LIGNOCELLULOSIC MATERIAL TO CHEMICALS AND FUELS}

\section{EXECUTIVE SUMMARY}

A direct conversion of cellulosic wastes, including resin-bonded furniture and building waste, to levulinate esters is being investigated with the view to producing fuels, solvents, and chemical intermediates as well as other useful by-products in an inexpensive process. The acid-catalyzed reaction of cellulosic materials with ethanol or methanol at 200?C gives good yields of levulinate and formate esters, as well as useful by-products, such as a solid residue (charcoal) and a resinous lignin residue. An initial plant design showed reasonable rates of return for production of purified ethyl levulinate and by-products.

In this project, investigations have been performed to identify and develop reactions that utilize esters of levulinic acid produced during the acid-catalyzed ethanolysis reaction. We wish to develop uses for levulinate esters that allow their marketing at prices comparable to inexpensive polymer intermediates. These prices will allow a sufficient rate of return to justify building plants for utilizing the waste lignocellulosics. If need is demonstrated for purified levulinate, the initial plant design work may be adequate, at least until further pilot-scale work on the process is performed.

Methanol and ethanol give the highest yields of levulinate esters and can be obtained at low cost of production. These esters are, therefore, preferred intermediates for conversion to many other products. The levulinates are ketoesters and, therefore, substrates for a variety of condensation and addition reactions at the ester and keto groups.

Reactions of ethyl levulinate with phenol were performed so that resin intermediate products (diphenolate esters) could be compared to those formed from levulinic acid (diphenolic acid), which had been previously prepared. Conditions for successful conversions to the diphenolate ester were developed. The ethyl diphenolate was converted to bis epoxy derivatives that reacted with hardener to give very tough pliable resin. An extremely tough polyurethane film was also produced from the diphenolate ester.

Levulinate ester was also efficiently converted into a glassy polymer via reaction with primary alkyl amines. This polymer may have application in coatings and films. Finally, the reaction of urea-formaldehyde with lignin was investigated as a model for the reaction occurring during the ethanolysis of particleboard. A potentially useful, extremely sticky resin was produced. 


\section{SUBTASK 4.1 - CONVERSION OF LIGNOCELLULOSIC MATERIAL TO CHEMICALS AND FUELS}

\section{INTRODUCTION}

Cellulosic biomass constitutes a huge and renewable resource that can be converted to chemical and fuel feedstocks. More efficient means for conversions of agricultural, forest, and construction waste are sought so that useful biomass-derived products can not only compete with or eventually replace petroleumbased products, but also supplement and complement the use of petroleum-based fuels as additives to promote more efficient burning and lower emissions. Using these cellulose resources effectively can thus reduce the disposal problems and pollution resulting from accumulation of cellulosic waste.

Some waste biomass is converted to useful products, like ethanol, in fermentation industries, and both fuel and chemical feedstocks have been prepared by acid-catalyzed thermal decomposition of cellulose (1). Heating lignocellulosic materials in aqueous acid hydrolyzes the cellulose to glucose and subsequently converts the glucose to levulinic (4-oxopentanoic) acid and formic acid. Advances in the thermal processing equipment resulted in improvements in the conversions of cellulosics to levulinic acid (2). The potential usefulness of levulinic acid from this degradative processing is demonstrated by the hydrogenation of levulinic acid to the alternative fuel additive, methyltetrahydrofuran (methylTHF), that is currently being promoted for use in P-fuel (3). Although levulinic acid exhibits poor solubility, it does increase octane numbers (4). Soluble derivatives of levulinic acid could be developed for oxygenate fuel additives that would not only increase the efficiency of the engines, but also lower emissions from the engines consuming these fuels. a-Angelica lactone is readily prepared by acid-catalyzed dehydration of levulinic acid and has been shown to increase octane ratings (5).

Several higher-value applications of the thermal degradation products from cellulosics are commercially developed or have been previously investigated. Furfural is derived from hemicellulose containing five-carbon sugars, and a large market exists as a chemical intermediate. Several years ago, diphenolic acid, a polymer intermediate, was prepared from levulinic acid (6) and used for synthesis of various coatings (7). Low-cost levulinate feedstocks resulting from process innovations could revive the levulinate industry and achieve the goal of converting waste to chemical products or intermediates for solvents, surfactants, and resins, including inexpensive binders.

Thermal processing of carbohydrates in nonaqueous solvents containing alcohols offers a direct conversion to levulinate esters that are useful for fuels and chemical intermediates (Figure 1). Fructose was converted to levulinate esters by heating with ethanol and a solid acid (8). When the reactions of lignocellulosics, such as wood and biomass wastes, were conducted in alcohol with strong acid catalysis in an autoclave at temperature greater than 195?C, the levulinate and formate esters of the alcohol were obtained, along with small amounts of furfural (9). A German patent for a chemical process for decomposition of cellulosic waste in alcohols was awarded (10). In the case of paper wastes and pulps,

a stirred precooking stage was required. At lower temperatures, incomplete conversion of cellulose occurred, and alkoxymethylfurfural was obtained. The 


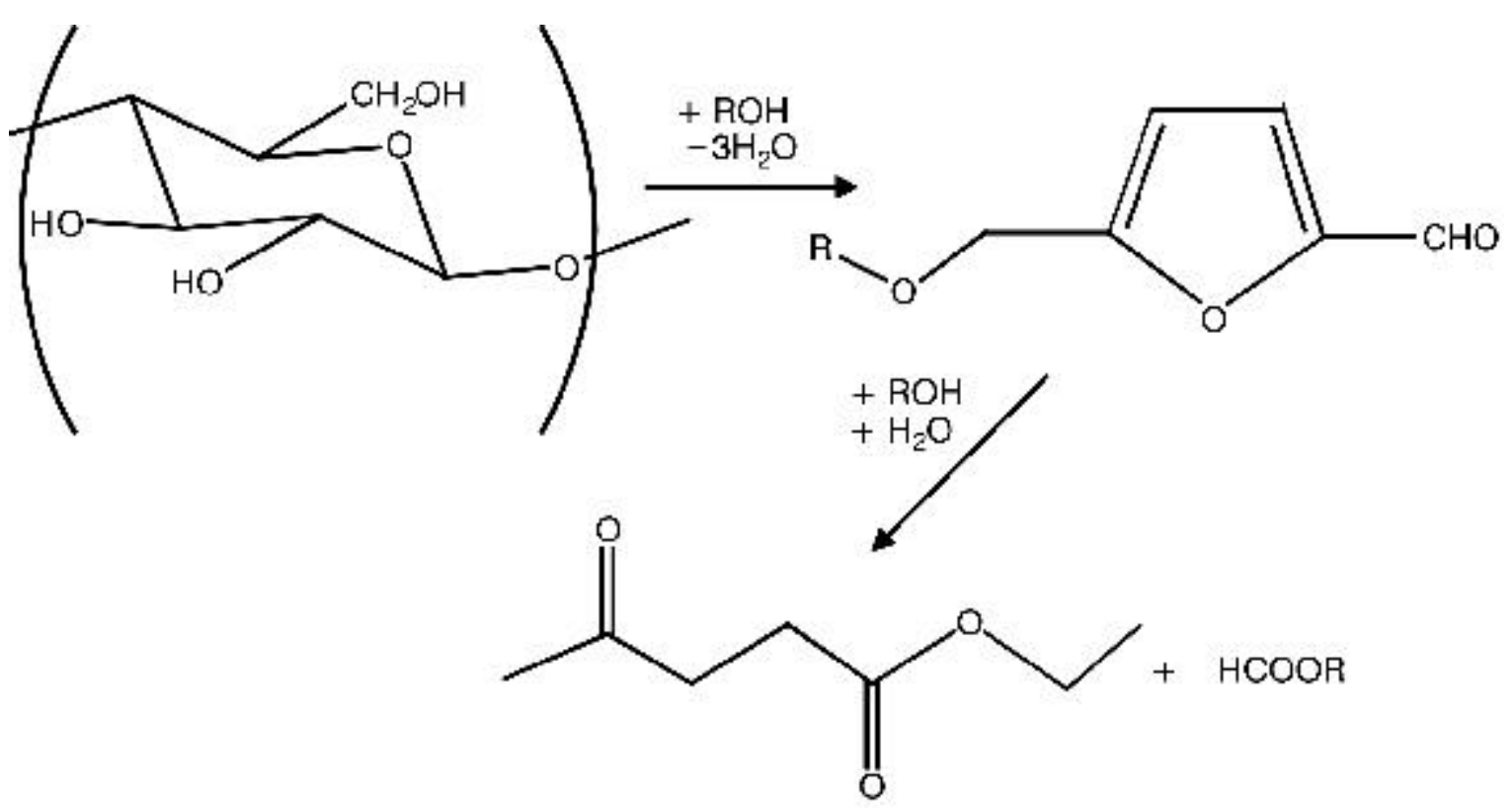

Ethyl Levulinate

EERC 5OIT60I.OOR

Figure 1. Conversion of cellulose to esters.

alkoxymethylfurfurals are presumed to be intermediates in the formation of alkyl levulinates and alkyl formates via cleavage of the carboxyaldehyde group on the furfural intermediate in a several step sequence.

Garves reported formation of insoluble humic residue at the higher temperatures (9). In earlier work, the acid-catalyzed reactions of ethanol with seed hulls and with chaf or straw waste at 200?C produced a charcoal product with modest surface areas. A significant part (20\%-30\%) of the cellulose is carbonized to charcoal, which is easily removed by filtration. Flash distillation of the excess alcohol and solvent extraction of the levulinate ester leave a resinous product consisting mainly of the lignin component of the biomass. Thus multiple marketable products are available from processing waste biomass with the acidic alcohols.

Particleboard from furniture manufacturing waste presents a unique disposal problem because of the urea-formaldehyde (UF) resin used in binding the wood particles and the polymer-laminated coatings. Many thousands of tons of wood wastes are produced in each furniture plant annually in the form of cut-off pieces and sawdust. The composite materials may form toxic and corrosive gases during combustion, and wastes must be landfilled or burned in an incinerator that safely consumes the resin and plastic materials as well as the wood. Landfilling this waste currently costs millions of dollars per year for a good-sized furniture plant. Thus an environmentally and economically feasible process for converting the composite wood waste to usable products is urgently needed.

As an alternative to landfilling or high-temperature incineration, the acid-catalyzed decomposition in alcohol efficiently and safely converts the composite materials to alkyl levulinate at moderate temperatures. 
The product composition obtained by heating particleboard chips in ethanol with sulfuric acid catalyst for 30 min at 200?C was similar to that obtained from ordinary wood treatment. The charcoal product was removed by filtration, the ethanol, water, and ethyl formate product flash distilled, and the ester levulinate separated from the resinous product by extraction into diethyl ether. In this case, the resinous products also contained the UF binding resins that were initially present in the waste board. The UF resin-derived components were intimately mixed with or chemically attached to the lignin resin; there was no way to extract and separate the lignin from the UF component.

For this processing, the waste particleboard was chipped but not ground to a fine meal. Milling of the particleboard is not necessary because the cellulosic material is rapidly decomposed in the acidcatalyzed reaction, thereby releasing the resin into the solvent and resulting in a more economical process. In the Garves patent (10), the wood and waste paper were first converted to a pulp and to a fluff, respectively. The moisture content of the as-received particleboard was $3 \mathrm{wt} \%$. Waste materials such as this with low moisture contents provide a good substrate for the alcohol reaction, since no drying is required.

\section{Experimental Details}

In a typical reaction, a mixture of $16 \mathrm{~g}$ of chipped laminated particleboard, $150 \mathrm{~mL}$ of ethanol, and $3 \mathrm{~g}$ of concentrated sulfuric acid was heated at 200 ? C for 30 minutes in a $300-\mathrm{mL}$ Parr pressure reactor. The mixture was allowed to cool to room temperature. The product mixture was filtered with a Buchner funnel, and the charcoal residue was washed with ethanol and dried to give $5.4 \mathrm{~g}$ of charcoal. The filtrate was neutralized with sodium bicarbonate and distilled to recover the excess ethanol and the water, ethyl formate, and trace amounts of diethyl ether produced in the reaction. To extract the levulinate ester, diethyl ether was added to the residue from the distillation, which contained a small amount of ethanol. The insoluble portion of the distillation bottoms gave the resin product $(3.3 \mathrm{~g})$. The ether soluble portion contained ethyl levulinate and a small amount of furfural. After stripping the ether on a rotary evaporator, the residue ( $4.5 \mathrm{~g}$ ) was vacuum-distilled to give ethyl levulinate $(3.8 \mathrm{~g})$ and impure furfural $(0.4 \mathrm{~g})$.

\section{Product Quality}

\section{Esters}

The purity of the ethyl levulinate fractions was determined by gas chromatography. The ether extract contained $85 \%$ ethyl levulinate, $10 \%$ furfural, and about $2 \%$ levulinic acid. The distilled ethyl levulinate cut was generally $97 \%$ to $98 \%$ ethyl levulinate with $2 \%$ levulinic acid. The crude extract should be appropriate

for use directly as a fuel oxygenate or for conversion to a fuel such as methylTHF. The distilled products would be suitable for use as a fragrance or for most chemical reactions. 


\section{Resin}

The recovered resin mixture was very tacky and has potential for recycling as a board resin. It was, however, very darkly colored and evolved a slight odor of levulinate ester. It may, therefore, be more appropriately used as a fine coal binder for making briquettes or a waterproof granular fuel. Additional work is being conducted to determine the potential for wood binder recycling, but considerable interest has been shown in the low-cost coal binder applications, and the market could easily consume all the resins that could possibly be produced.

\section{Carbon}

The charcoal is moderately active even without further steam activation. The surface area was determined by the iodine number method ( $456 \mathrm{mg} \mathrm{I}_{2} / \mathrm{g}$ ). Steam activation converted the initial charcoal product to a higher area activated carbon with the iodine number $540 \mathrm{mg} \mathrm{I}_{2} / \mathrm{g}$, but with loss of about half of the carbon. The initial charcoal should be adequate for a number of decolorizing and other aqueous treatments.

\section{Advantages of the Cellulose Degradation in Ethanol}

Performing the reaction of cellulosic materials in ethanol rather than water offers the advantage of a more direct route to the ester. This provides a convenient one-step reaction to produce a fuel oxygenate additive at minimal cost, compared with two-step reactions involving formation of the acid in the aqueous conditions.

A second advantage of the ethanol process is the ease of product workup into the various product fractions. The charcoal product is filtered from the soluble products; the ethanol solvent, ethyl formate, and product water are readily stripped; and the ethyl ester easily removed from the resin and distilled without decomposition. In contrast, the purification of levulinic acid is more difficult from a water solution, and consequently, the production of levulinic acid is limited.

\section{Particleboard Waste Process Design}

A schematic for a waste particleboard processing is shown in Figure 2. This process avoids heating the resin in the presence of ethyl levulinate, which generates a highly insoluble resin product. Instead, the ethyl levulinate is extracted from the resin and subsequently vacuum-distilled to purify it.

\section{Plant Design}

A preliminary plant design and cost analysis for the particleboard processing was performed in another project (11). This projection used extensive distillation equipment to produce pure ester products from waste particleboard input at 33,000 tons/year. Product output is shown in Table 1. Assuming that the

value for the ethyl levulinate is $\$ 0.15$, based on fuel additive use, the analysis showed that the after tax 


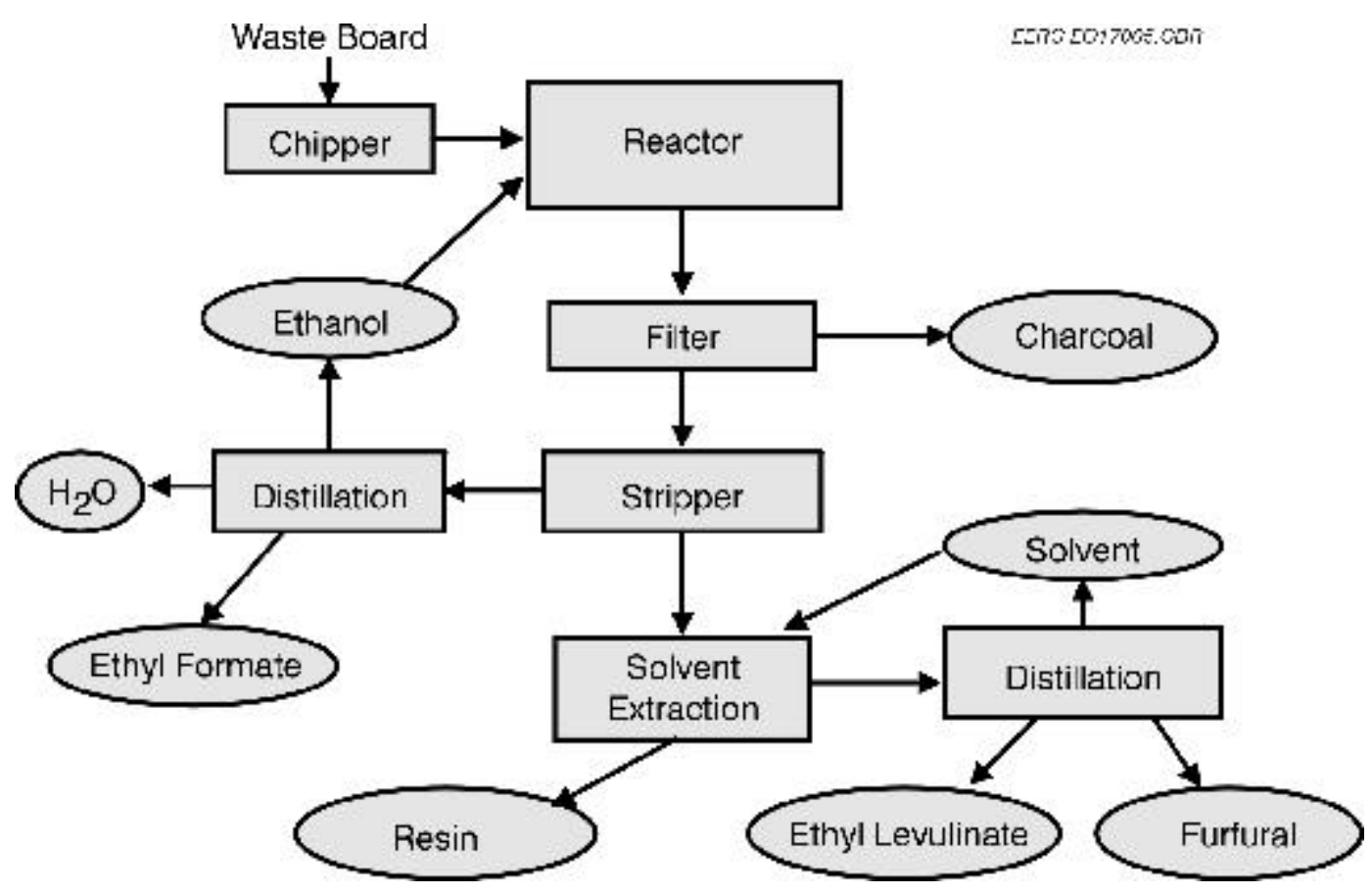

Figure 2. Particleboard waste process.

TABLE 1

Process Products for 33,000-ton Plant

\begin{tabular}{lcc}
\hline Product & Yearly Production, million $\mathrm{lb}$ & Est. Market Value, $\$ / \mathrm{lb}$ \\
\hline Ethyl Levulinate & 15 & $0.15-60$ \\
Ethyl Formate & 7 & 0.50 \\
Furfural & 1 & 0.70 \\
Charcoal & $10-22$ & 0.25 \\
Resin & 15 & 0.10 \\
\hline
\end{tabular}

internal rate of return (IRR) would be $3.4 \%$, which is not enough to justify building a plant for this market. If, however, the value of ethyl levulinate as a solvent and chemical intermediate could be increased to $\$ 0.60 / \mathrm{lb}$, the sensitivity analysis showed that the IRR would be an acceptable $20 \%$.

Thus more development work needs to be done to understand the value of the reaction products (esters, charcoal, and recovered resin) in various chemical markets and determine if fuel use is the only option for developing the large market needed for the ethyl levulinate produced. If the fuel oxygenate 
additive market is the only large market option, less distillation processing would be required, and revision of the process and plant design is needed. The production cost could be much lower, since the cost of the distillation columns was $65 \%$ of the purchased equipment cost.

This projection used extensive distillation equipment to produce pure ester products, but assumed a large market would exist only for fuel additives, which would not require a pure ester. Thus revision of the process cost/market analysis is appropriate, but more development work needs to be done to understand the value of the alcohol reaction products (esters, charcoal, and recovered resin) in various chemical markets and determine if fuel use is the only option for developing a large market.

\section{RESULTS AND DISCUSSION}

\section{Conversions of Alkyl Levulinates}

A major goal for promoting commercialization of the alcohol processing of waste particleboard and plywood is the expansion of markets for alkyl levulinates. The major current market for alkyl levulinates is in fragrances, where the ethyl levulinate has a value of about $\$ 10 / \mathrm{lb}$. Butyl levulinate is also used, but the market is relatively small for both esters.

Both the keto and the carboxylate functional groups of levulinic acid and esters are available for derivatization, and a large number of transformations of either or both groups have been investigated in previous studies (12-15). Levulinate esters of higher alcohols and glycols have been used as plasticizers, especially for vinyl chloride polymers (16). We previously investigated the easy tranesterification reactions of methyl and ethyl levulinate to a number of ester products (17).

\section{Condensation Reactions}

Levulinic acid is known to react with aldehydes at carbon atoms adjacent to both the acid (a) and keto ( $\beta$ and $d$ ) groups to form a mixture of the a-, $\beta-$, and $d$ - alkylidene or arylidene derivatives $(12,13$, 15). With excess formaldehyde, levulinic acid is substituted with five or six hydroxymethyl (methylol) groups, and cyclization to a lactone occurs (18). These condensation reactions could be utilized to produce inexpensive resins from the crude ethyl levulinate obtained from waste particleboard without distillation. Another reason for studying the reactions of the ester with aldehydes is to determine the potential for similar reactions occurring during the cellulose degradation reaction or the subsequent workup of products where aldehydes such as furfural are present.

The reactions of ethyl levulinate with several aldehydes were examined. The reaction of formaldehyde with ethyl levulinate was conducted with dilute sulfuric acid catalyst; the methylol derivatives undoubtedly formed but were not isolated. The reaction with formaldehyde in ethanol solution formed a sticky resin, which was an excellent binder. 
The reaction of ethyl levulinate with furfural gave a condensation product; the major isomer is presumed to be the d-furfurylidenelevulinate ester, since the acid-catalyzed reaction of furfural with levulinic acid produces this isomer (19). Some of this reaction could occur during the preparation of ethyl levulinate, since furfural and acid catalyst are present, but no furfurylidenelevulinate ester was detected in the ether extract. Thus if condensation reactions occur, the products stay in the char or the resin products and are likely of higher molecular weight.

In order to selectively obtain the a-substituted condensation products from levulinate esters, it is necessary to protect the ketone group. Ethyl levulinate reacts with one mole of ethylene glycol to form the cyclic ketal. Condensation of the protected ester with benzaldehyde gave the a-benzylidene ester (Figure 3).

\section{Resin Intermediates}

The acid-catalyzed condensation of ethyl levulinate with urea was investigated. After heating the mixture, ethanol was evolved, so it is presumed that the condensation involved both carbonyl groups of the levulinate ester. The reaction produced a sticky resin that was soluble in alcohol.

A similar reaction of ethyl levulinate was conducted with a preformed soluble UF resin. The acidcatalyzed reaction incorporated the levulinate into the resin structure forming an insoluble mass. This reaction does not occur to a large extent during the initial particleboard degradation owing to the large volume of ethanol solvent; however, it can cause a problem in the workup of the products after the ethanol has been removed. The reaction explains the failure of attempts to distill ethyl levulinate directly from the levulinate-resin product mixture without prior extraction of the ester from the resin. These attempts resulted in low ester yields and the formation of intractable resin. Thus by extracting the ester, we can avoid the inadvertent condensation reaction with the resin.

The conversion of waste particleboards in ethanol/acid produces large amounts of a resinous product containing the original UF bonding resin of the board and much of the lignin derived from the wood. In order to understand the formation and properties of this resinous material, we have conducted a model reaction in the laboratory, reacting an inexpensive commercial UF resin with a lignin preparation to produce an extremely sticky resin product (now the UF-lignin resin) that resembles the product obtained from the particleboard ethanolysis reaction. Neither the starting UF resin nor the lignin was at all sticky. Not only does this experiment support our concept of how the ethanolysis reaction products are formed, it allows us to prepare a large amount of similar resin for testing as a wood or other binder, so that we do not need to run the ethanolysis reaction at a very large scale for the present purposes. The very sticky UF-lignin resin has potential for recycling as a particleboard resin or could be used as a fine coal binder (briquette or waterproof granular). Mild thermal treatment causes the UF-lignin resin to thermoset to a very tough material. 


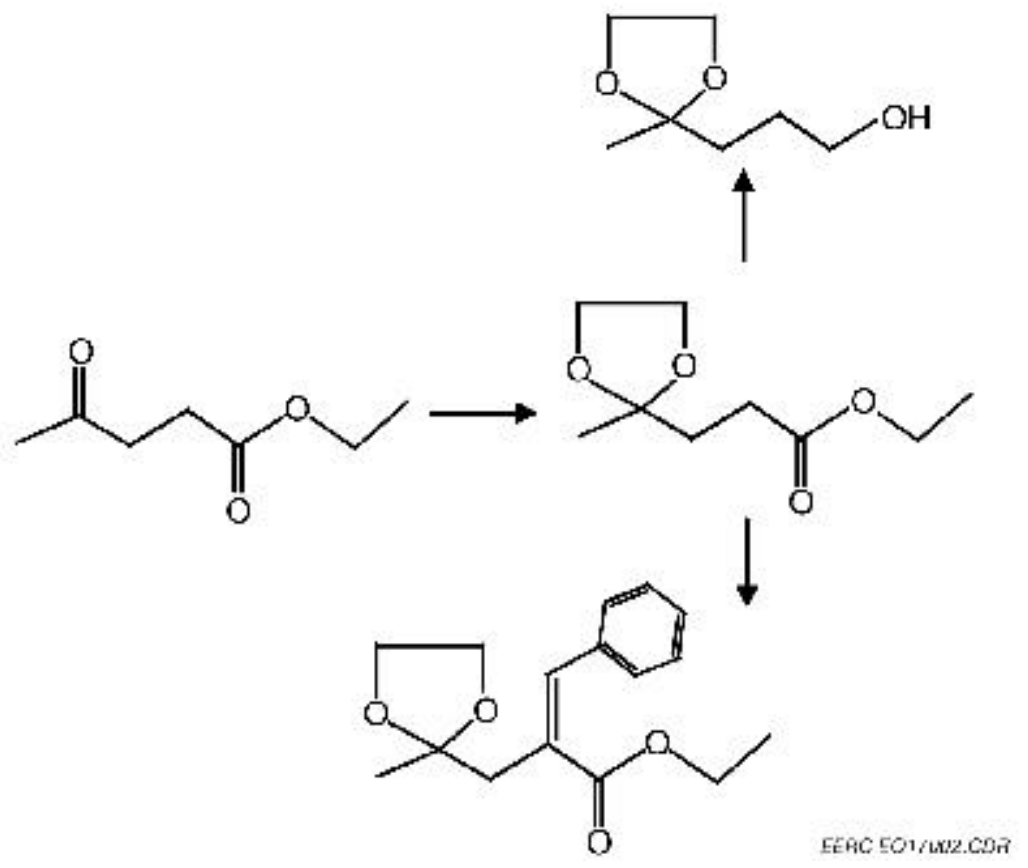

Figure 3. Formation of aldehyde condensation product.

\section{Diphenolate Resins}

Levulinic acid condenses with two moles of phenol to give 4,4-bis-(4'-hydroxyphenyl)-pentanoic acid (diphenolic acid). This bisphenol intermediate was used to prepare several types of resins, including phenolic-formaldehyde, epoxy, polycarbonate, polyester, and polyurethane types (7). Ethyl levulinate should undergo a similar reaction with phenol to give the diphenolate ester (Figure 4). Further conversions to resins could then be performed with the diphenolate ester intermediate. Polymeric linkages can be effected through the two phenolic groups in typical bisphenolic syntheses, or the carboxylate can be used as a third linkage in cross-linked resins. Alternatively, the ester functionality can be easily transformed to amide and other groups with interesting binding properties. An advantage in this type of polymer is the extension of the ester or amide functionality away from the polymer backbone, so that it can effectively interact with and adhere to a surface.

The reaction of ethyl levulinate with phenol (two moles) was investigated with the goal of producing a useful diphenolate resin intermediate as described above. However, the reaction of the ester under conditions analogous to those used for levulinic acid did not produce much of the desired ethyl diphenolate product. Reaction conditions were modified, and after several attempts, high yields of the ester product were obtained, in fact $95 \%$ yields compared with $67 \%$ for the levulinic acid. The most efficient method for synthesis of ethyl 4,4-bis-(4-hydroxyphenyl)-pentanoate (ethyl diphenolate) from ethyl levulinate was devised using concentrated sulfuric acid catalyst, followed by dilution with ethanol at the end of the reaction time. The small excess amount of reactants remaining were steam-distilled off the product. 


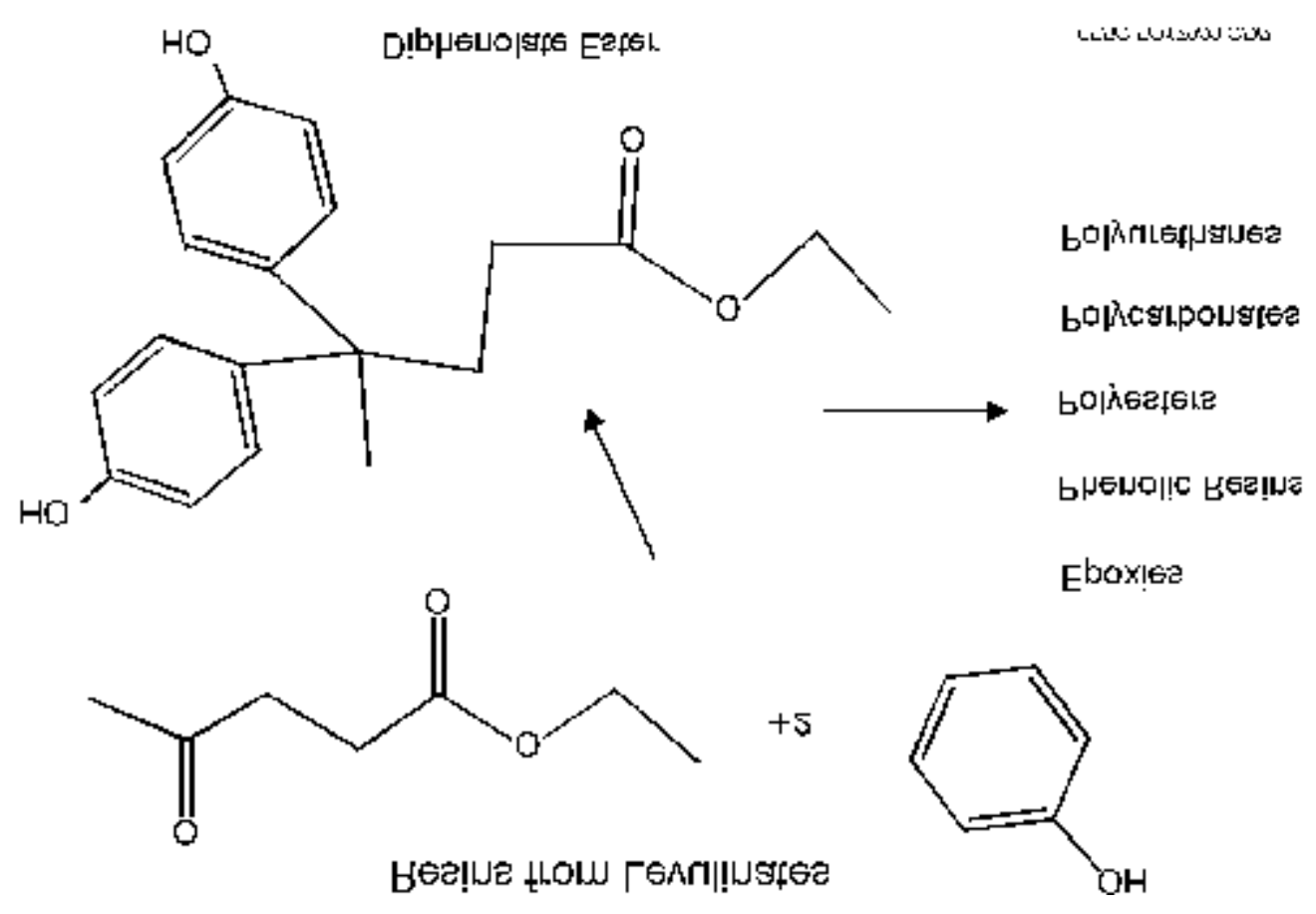

Figure 4. Formation and reactions of diphenolate ester.

The ethyl diphenolate was reacted with epichlorohydrin to give the corresponding bis epoxy derivatives. Using 2 moles of epichlorohydrin, the reaction produced a rubbery material, insoluble in most solvents. It decomposed rather than melted when heated to high temperatures. It is likely that a glycol intermediate cross-linked at the ester group to form the rubber.

When a large excess of epichlorohydrin was used in the reaction, the cross-linking was avoided, and the major product was the bisglycidylphenylpentanoate. This product resembles the bisphenol A used for making most epoxy resins. When the bisglycidylphenylpentanoate was mixed in equal portions with diamine hardener, a hard but pliable resin was produced. The resin retained a stickiness after curing at ambient conditions in contrast to the commercial bisphenol A resin. Heat- curing of the new resin gave a very hard material. The bonding strength of the resins (ambient and heat-cured) were tested in a hydraulic press and compared with the commercial bisphenol A epoxy resins. The shear strength appeared to be similar, but the force required to break the bonding at a 90 ? angle was higher for the commercial resin. Owing to the greater pliability and lower brittleness of the new resin, its use in floor coverings may be feasible.

Polyurethane resins were also produced from the ethyl diphenolate under a variety of conditions. These reactions used a bisisocyanate to react with the phenolic groups of the ethyl diphenolate. An extremely tough film coating was produced by reacting the bisisocyanate with the ethyl diphenolate in a solvent and allowing the solvent to evaporate. 


\section{Polylactam Resins}

Reactions of the ethyl levulinate with primary amines was also investigated with the view to producing an unsaturated lactam that should be exceptionally reactive as a monomer for addition polymers and copolymers with polyamide properties. Levulinic acid is converted with heat and acid to an unsaturated lactone, angelicalactone. Reaction of the lactone with methylamine results in formation of the unsaturated lactam, allegedly with an exocyclic double bond. The radical-initiated polymerization of the lactam has not been reported, but it should go readily, especially if it is really the exocyclic isomer. The reaction of the ethyl levulinate with methylamine should also result in formation of an unsaturated lactam. However, the reaction of the ester did not proceed with the same ease as did the reaction of the lactone with methylamine to give the lactam. To facilitate the conversion to unsaturated lactam, the initial product was heated at various temperatures. The result of these experiments was the direct production of a resin product rather than the lactam that should have distilled out under vacuum conditions. It is not known whether the unsaturated lactam formed and polymerized (self-initiated radical addition) or some other condensation polymerization reaction occurred. In either case, the polymerization product is a glassy material at room temperature and may be useful for films and coating.

\section{CONCLUSION}

The successful reactions investigated in this project support the idea that the ester products from conversion of cellulosic wastes in alcohol at 200?C can be useful intermediates for producing a variety of resins and thereby increase the market for the esters in the chemical industry. The costs will be comparable

to those for bisphenol resins currently produced, but properties of the new resins will be different, especially with regard to pliability and brittleness.

\section{REFERENCES}

1. Dunlap, A.P. U.S. Patent 2,813,900, 1957.

2. Fitzpatrick, S. U.S. Patents 4,897,497, 1990; 5,608,105, 1997.

3. Parkinson, G., Ed. Chem. Eng. 1998, Sept., 25.

4. Eckert, G.W. U.S. Patent 3,074,787, 1963.

5. Thomas, J.J.; Barile, R.G. Prepr. Pap-Amer. Chem. Soc., Div. Fuel Chem. 1983, 1461.

6. Bader, A.R.; Kontowicz, A.D. J. Amer. Chem. Soc. 1954, 76, 4465.

7. Bader, A.R. U.S. Patent 2,933,472, 1960.

8. Brown, D.W.; Floyd, A.J.; Kinsman, R.G.; Roshan-Ali, Y.J. Chem Tech. Biotechnol. 1982, 32, 920.

9. Garves, K. J. Wood Chem. \& Technol. 1988, 8, 121.

10. Garves, K. German Patent DE 3621517 A1, 1988.

11. Mann, M. Personal communication, 1999.

12. Kitano, M.; Tanimoto, F.; Okabayashi, M. Chem. Economy \& Eng. Rev. 1975, 7, 25.

13. Quaker Oats Co. Levulinic Acid (Bulletin 301A). 
14. Shilling, W.L. Tappi 1965, 48, 105A.

15. Leonard, R.H. Ind. \& Eng. Chem. 1956, 48, 1331.

16. Emerson, W.S.; Langley, R.I. U.S. Patent 2,581,008, 1952.

17. Olson, E.S.; Kjelden, M.R.; Schlag, A.J.; Sharma, R.K. Levulinate Esters from Biomass Wastes. In Chemicals and Materials from Renewable Resources; Bozell, J.J., Ed.; Amer. Chem. Soc., 2001; p 51.

18. Olsen, Acta Chem. Scand. 1955, 9, 101.

19. Urban, R.S. U.S. Patent 2,688,621, 1954. 